\title{
Interaction between Antarctic sea ice and synoptic activity in the circumpolar trough: implications for ice-core interpretation
}

\author{
Elisabeth SCHLOSSER, ${ }^{1}$ Jordan G. POWERS, ${ }^{2}$ Michael G. DUDA, ${ }^{2}$ \\ Kevin W. MANNING ${ }^{2}$ \\ ${ }^{1}$ Institute of Meteorology and Geophysics, University of Innsbruck, Innrain 52, A-6020 Innsbruck, Austria \\ E-mail: Elisabeth.Schlosser@uibk.ac.at \\ ${ }^{2}$ Earth System Laboratory, National Center for Atmospheric Research, PO Box 3000, Boulder, CO 80307-3000, USA
}

\begin{abstract}
Interactions between Antarctic sea ice and synoptic activity in the circumpolar trough have been investigated using meteorological data from European Centre for Medium-Range Weather Forecasts (ECMWF) Interim Re-analysis and sea-ice data from passive-microwave measurements. Total Antarctic sea-ice extent does not show large interannual variations. However, large differences are observed on a regional/monthly scale, depending on prevailing winds and currents, and thus on the prevailing synoptic situations. The sea-ice edge is also a preferred region for cyclogenesis due to the strong meridional temperature gradient (high baroclinicity) in that area. The motivation for this study was to gain a better understanding of the interaction between sea-ice extent and the general atmospheric flow, particularly the frequency of warm-air intrusions into the interior of the Antarctic continent, since this influences precipitation seasonality and must be taken into account for a correct climatic interpretation of ice cores. Two case studies of extraordinary sea-ice concentration anomalies in relation to the prevailing atmospheric conditions are presented. However, both strong positive and negative anomalies can be related to warm biases in ice cores (indicated by stable-isotope ratios), especially in connection with the negative phase of the Southern Annular Mode.
\end{abstract}

\section{INTRODUCTION}

Sea ice is an important component of the climate system for several reasons. First, it strongly influences the heat budget of the ocean-atmosphere system by insulating the ocean from the atmosphere, thus considerably reducing the turbulent heat and moisture fluxes (Simmonds and others, 2005). Second, the presence or absence of sea ice changes the albedo of the surface by up to $80 \%$, affecting the shortwave radiation balance of the surface. Whereas snowcovered sea ice reflects up to $90 \%$ of incoming solar radiation, the open ocean absorbs up to $90 \%$ of such radiation. Third, brine rejection during the formation of sea ice increases the density of surface water, and thus enhances the thermohaline circulation and hence the vertical mixing of the ocean. This ultimately drives the three-dimensional global oceanic circulation (Wadhams, 2000).

Because of the influence of sea ice on the energy balance of the ocean-ice-atmosphere system, the meridional gradient of air temperature is large at the sea-ice edge, at least at lower levels. In particular in the Southern Hemisphere, where there are no constraints on sea-ice extent from continents, this means that the sea-ice edge is a zone of high baroclinic instability of the atmosphere, and thus a preferred zone for cyclogenesis. However, the meridional temperature gradient not only depends on oceanic conditions, but also on the radiation balance, which, in sum, leads to the wellknown semi-annual oscillation (SAO) (Schwerdtfeger, 1960; Van Loon, 1967) of the low-pressure trough that surrounds the Antarctic continent. The temperature contrast between middle and high latitudes is found to have two maxima around the equinoxes, leading to increased cyclonic activity at these times. Thus, the circumpolar low-pressure trough is strongest and situated farthest south in spring and autumn. This means that in spring the zone of highest baroclinicity is situated considerably south of the sea-ice edge. However, the SAO shows high temporal variability on interannual to decadal timescales. Simmonds and Jones (1998) showed that in both the mid- and high latitudes the temporal variability of the SAO of pressure is statistically related to the variability of the high-latitude temperature gradient. Thus, to understand the temporal variability of pressure in the southern extratropics on annual to decadal timescales we need to understand the large-scale variability of the temperature gradients, which are strongly influenced by the presence of sea ice.

On the other hand, the synoptic activity in the circumpolar trough influences the sea-ice formation and distribution. Sea-ice extent depends on both the thermodynamic and dynamic conditions. Usually, low-pressure systems move westward within the circumpolar trough. The clockwise rotation of the cyclones leads to predominantly westerly winds at their northern sides, and easterly winds at their southern sides. Taking into account the near-surface part of Ekman transport, the resulting net sea-ice transport is to the northeast (at the northern side of cyclones) and to the southwest (at the southern side). Depending on the location of the cyclone center relative to the sea-ice edge, this leads to a divergence or convergence of the sea ice (Enomoto and Ohmura, 1990). Whereas convergence usually means higher sea-ice concentration but smaller sea-ice extent, divergence can mean both smaller and larger sea-ice extent (lower and higher concentration) depending on the prevailing temperatures. In winter or in coastal areas it can lead to increased new ice production, and thus to an increase in sea-ice extent, whereas in spring/summer or in the marginal zone it can accelerate the melting of the ice, thus reducing sea-ice extent and concentration. However, the influence of the synoptic-scale forcing on the sea-ice drift compared to 
oceanic forcing also depends on the geographic area (Heil and others, 2009).

\section{MOTIVATION OF THE STUDY}

The ongoing discussion about climate change, and the increasing speed with which climate change occurs in some regions of the world, has intensified our efforts to understand the reasons for it and to assess possible future climate changes. However, to fully understand the climate system and to discuss projections for the future, we need to be able to explain the climate changes of the past. To do this, we need to fully understand the climate system. Analysis of deep ice cores drilled in Greenland and Antarctica has helped to improve our knowledge of past climate and understanding of the relationships of the different components of the climate system, but, for a correct climatic interpretation of the various properties measured in these ice cores, it is also necessary to understand the processes that led to the formation of the ice. The ice of the Antarctic ice sheet developed from snow that has been compressed and densified under its own weight, so it is nothing but former precipitation. Wet deposition of various chemical components is also dependent on precipitation processes.

One of the most successful methods for deriving paleotemperatures is the analysis of the stable water isotopes of ice cores. A linear relationship between the annual mean stable-isotope ratio of the ice and the annual mean air temperature at the deposition site has been found by sampling snow of different temperature regimes (e.g. on traverses). This relationship is usually used to derive direct climate information from ice cores: high stable-isotope values correspond to warm periods and low values to cold periods. However, it has also been found that this spatial relationship and the temporal relationship between air temperature and stable-isotope ratio are different. Stable water isotope ratios (e.g. $\delta^{18} \mathrm{O}$ ) change during evaporation and condensation processes due to the slightly different masses, and thus physical properties, of the light and the heavy isotopes, respectively. Thus, the ratios are dependent on the precipitation history, namely the origin and transport of the moisture, including entrainment of additional moist air masses between the first moisture source and the deposition site. In a study with an atmospheric general circulation model (GCM) that included a stable-isotope module, Noone and Simmonds (2002b) found that typically $<20 \%$ of the modeled $\delta^{18} \mathrm{O}$ variance could be explained by temperature changes.

For a correct interpretation of the measured $\delta^{18} \mathrm{O}$, the precipitation must be evenly distributed over all seasons. A clear climatic signal requires an even seasonal distribution of precipitation, in order to ensure that the temperature information stems equally from all parts of the year.

Schlosser (1999) and Schlosser and Oerter (2002) investigated the relationship between the stable oxygen isotope ratio $\left(\delta^{18} \mathrm{O}\right)$ of fresh snow samples and the local air temperature at Neumayer station, Dronning Maud Land (DML), Antarctica. They showed that seasonality of precipitation strongly influenced the quality of that relationship. This was also demonstrated in a model study by Noone and Simmonds (1998) and Noone and others (1999). An even precipitation distribution is essentially given if precipitation mainly consists of so-called diamond dust or clear-sky precipitation, which has been shown to feature some seasonality but to depend only weakly on synoptic influences (Bromwich, 1988).

However, several studies (Noone and Simmonds, 1998; Noone and others, 1999; Reijmer and Van den Broeke, 2003; Birnbaum and others, 2006; Schlosser and others, 2008, 2010) have shown that even in the interior of the Antarctic continent, precipitation can be highly episodic, with large fractions of the total annual accumulation being due to a few high-precipitation events per year. As yet, however, it is not known, for either the present or for past climate periods, whether these events are randomly distributed over the seasons or whether certain seasons are preferred. A much larger sea-ice extent during glacial periods (Gersonde and others, 2005; Röthlisberger and others, 2010) might have been related to systematically different atmospheric flow patterns. For example, a more northerly sea-ice edge might have led to less winter precipitation in the southern parts of the continent, meaning a warm bias in the stable-isotope ratio of ice cores drilled in those parts of Antarctica, since the stable-isotope profile would lack the contribution of the colder months of the year. This means that an actual decrease in air temperature would appear as a general warming trend.

Thus sea ice greatly influences ice-core properties. Apart from the direct influence on sea salt and other oceanic chemical components measured in ice cores, it affects all ice-core properties related to precipitation by influencing atmospheric processes.

For a correct climatic interpretation of ice cores, we need to understand the interactions between sea ice and atmosphere as exactly as possible. However, the complexity of the problem hampers a straightforward approach. Without a model, it is not possible to investigate sea-ice conditions that correspond to glacial climate conditions. Thus, to gain a better understanding of the atmospheric processes that influence sea-ice distribution, extreme situations with extraordinary sea-ice concentration anomalies within the instrumental/satellite period are investigated. The largest anomalies in sea-ice extent/concentration are found in summer. In the present study, a highly positive and a highly negative anomaly in sea-ice concentration observed in December 2001 and December 2002, respectively, in the Weddell Sea are compared and related to the prevailing atmospheric conditions. Rather than a statistical analysis, a process study of sea-ice-atmosphere interaction and its consequences for ice-core interpretation are discussed.

\section{PREVIOUS WORK}

Interactions between sea ice and atmosphere have been studied by various authors with sometimes seemingly contradictory results. However, the complexity of the processes allows differentiation between causalities of different importance, which all act together and exhibit temporal and spatial differences. It is beyond the scope of this study to give a comprehensive overview of the wide area of sea-ice-atmosphere interactions.

Simmonds and $\mathrm{Wu}$ (1993) investigated the reaction of cyclones in the Southern Hemisphere to reductions in winter Antarctic sea-ice concentration using a GCM. They found an increase in the number of cyclones with decreasing sea-ice extent and a southward shift of the location of the cyclones. The model also yielded enhanced cyclogenesis in the western Weddell Sea and an increase of cyclogenesis in 
September 2001

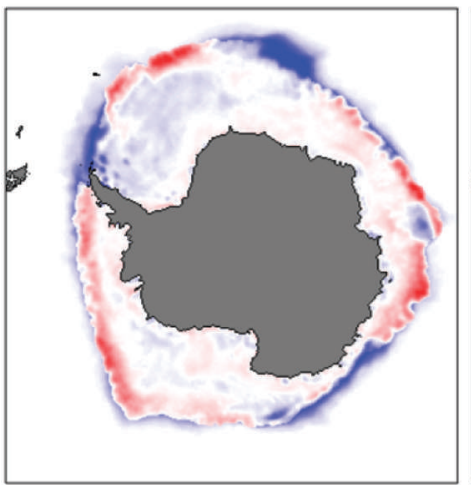

December 2001

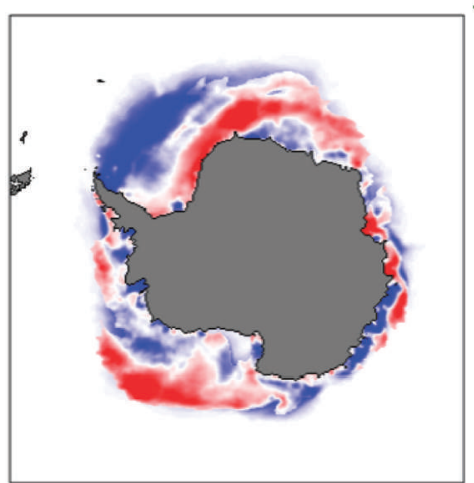

October 2001

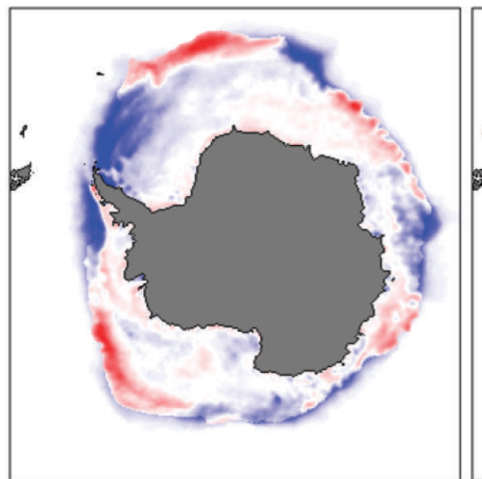

January 2002

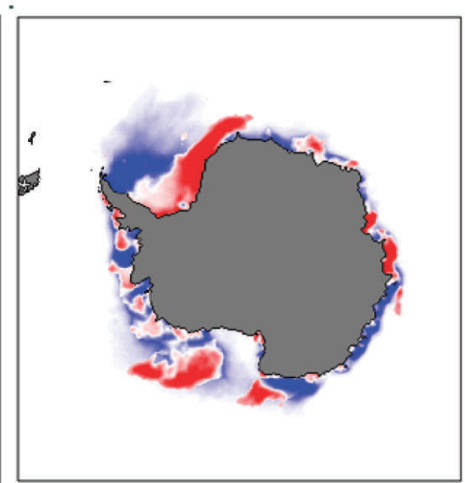

November 2001

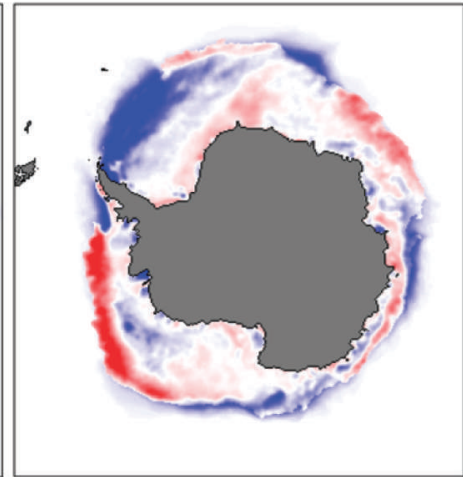

$>50$

45

40

35

30

25

20

15

10

5

0

5

$-10$

$-15$

$-20$

$-25$

$-30$

$-35$

$-40$

$-45$

$<-50$

$\%$

Fig. 1. Anomalies of monthly sea-ice extent for September 2001-February 2002 (data from NSIDC (W. Meier and others, http://nsidc.org/ data/nsidc-0051.html)) (ftp://sidads.colorado.edu/DATASETS/NOAA/G02135/).

most regions south of $65^{\circ} \mathrm{S}$. The southward shift of the cyclone activity was confirmed by Pezza and others (2008), who related Antarctic sea-ice extent to the Southern Annular Mode (SAM; Marshall, 2003), the El Niño Southern Oscillation (ENSO) and southern Australia rainfall. The relationship between ENSO and Antarctic sea ice has also been investigated by Yuan (2004), who found the strongest teleconnection between ENSO and sea ice in the so-called Antarctic Dipole, which is characterized by an out-of-phase relationship between sea ice and surface temperature anomalies in the South Pacific and South Atlantic.

Godfred-Spenning and Simmonds (1996) examined the relationship between Antarctic sea ice and Southern Hemisphere extratropical cyclones on a seasonal timescale. No general link between sea ice and cyclones was found, and generally the influence of the atmosphere on sea ice seemed to be stronger than vice versa. However, they stated that winter cyclogenesis was most strongly linked to local sea ice. They also argued that the forcing by cyclonic wind stresses may be less important than the associated incursions of warmer or colder air in forcing large-scale sea-ice decay or growth. With this point in mind, it would be of interest to investigate the long-term effects of anticyclonic ridging on sea-ice extent.

This was done on a regional scale by Turner and others (2002), who studied meteorological and sea-ice conditions in the Weddell Sea in the 2001/02 austral summer. They found that an extraordinarily long-lived blocking situation connected to an amplified wavenumber-3 pattern led to the worst sea-ice conditions in the southern and western Weddell Sea, which considerably complicated the yearly provisioning of the British Antarctic base Halley. They did not take into account the near-surface Ekman transport, but concluded that the prevailing northwesterly wind over the Weddell Sea caused exceptionally high ice concentrations across the southwest Weddell Sea and little ice advection along the coast of Coats Land, where Halley is situated. They also stated that this anomalously stable weather situation caused positive temperature and precipitation anomalies at several sites across Antarctica due to the meridional heat and moisture transport associated with the amplified waves.

\section{DATA}

\section{Sea-ice data}

Information about Antarctic sea-ice concentration is available from the US National Snow and Ice Data Center/ World Data Center for Glaciology (NSIDC/WDC), University of Colorado, Boulder. NSIDC provides a wide variety of sea-ice data derived from passive microwave sensors and other sources. For our purpose, sea-ice concentrations measured by the Nimbus-7 Special Sensor Microwave/Imager (SMMR) and the US Defense Meteorological Satellite Program (DMSP) scanning multichannel microwave radiometer (SSM/I) were mainly used. These data are available from October 1978 until today, with a temporal resolution of 1 day and a spatial resolution of $25 \mathrm{~km}$ (true at $70^{\circ}$ latitude) (W. Meier and others, http:// nsidc.org/data/nsidc-0051.html).

Further information about NSIDC sea-ice products can be found at http://nsidc.org/data/sea_ice.html. 


\section{Meteorological data}

Since observational data from Antarctica are still sparse, atmospheric data are taken from the European Centre for Medium-Range Weather Forecasts (ECMWF) Interim Reanalysis (ERA-Interim). Reanalyses are produced using fixed, modern versions of the forecasting model and the data assimilation systems developed for numerical weather prediction. Thus they are more suitable than the operational analyses for studies on a longer timescale. The relatively new ERA-Interim shows considerable improvements compared to the previous ERA-40, including higher resolution, improved model physics, a better hydrological cycle, fourdimensional variational data assimilation and variational bias correction of satellite radiance data. The latter is particularly important because of the scarcity of direct meteorological measurements in the polar regions, especially above the polar oceans (Screen and Simmonds, 2010). For the present study, ERA-Interim fields of surface wind, surface pressure, surface temperature and $500 \mathrm{hPa}$ geopotential height are used. To investigate the relationship between sea ice and precipitation in DML, data from the Antarctic Mesoscale Prediction System (AMPS) were used rather than ERA-Interim data. AMPS has been developed by the US National Center for Atmospheric Research (NCAR) and the Polar Meteorology Group of the Byrd Polar Research Center at The Ohio State University. For the investigated time period, AMPS employed a version of the MM5, a mesoscale atmospheric model, that was specially adapted for polar regions. AMPS archive data have been used by Schlosser and others $(2008,2010)$ in their precipitation studies. In spite of several changes in model configuration and resolution, AMPS data are used to investigate precipitation. They are more suitable for our investigation than the reanalysis data due to their much higher resolution of $30 \mathrm{~km}$ compared to $1.5^{\circ}$ of the ERA-Interim data.

\section{CASE STUDIES}

\section{Extremely negative anomaly in sea-ice concentration (December 2001)}

In this study, we concentrate on the Weddell Sea area for two reasons: (1) it has a large potential for deviations from the long-term mean, since it is one of the few regions of Antarctica that show substantial amounts of multi-year ice and covers a broad latitude range; (2) we are interested in the influence of the Weddell Sea on the adjacent parts of the continent, namely DML, because of the deep ice-core drilling carried out there in frame of the European Project for Ice Coring in Antarctica (EPICA; e.g. EPICA Community Members, 2006).

Figure 1 shows monthly Antarctic sea-ice concentration anomalies for September 2001-February 2002. In September 2001 most parts of the Weddell Sea show concentrations close to average; at the northern edge, there are even positive anomalies. This changes, at accelerating speed, until December. In December, a strong negative anomaly in sea-ice concentration and extent is seen in the northwestern Weddell Sea, whereas in the southeastern, coastal areas high positive anomalies are found. This is due to dynamic processes related to the prevailing weather situation (see below).

In Figure $2 \mathrm{a}$ and $\mathrm{b}$, respectively, the monthly mean surface pressure and the $500 \mathrm{hPa}$ geopotential height from the ERAInterim are shown. A low-pressure system west of the
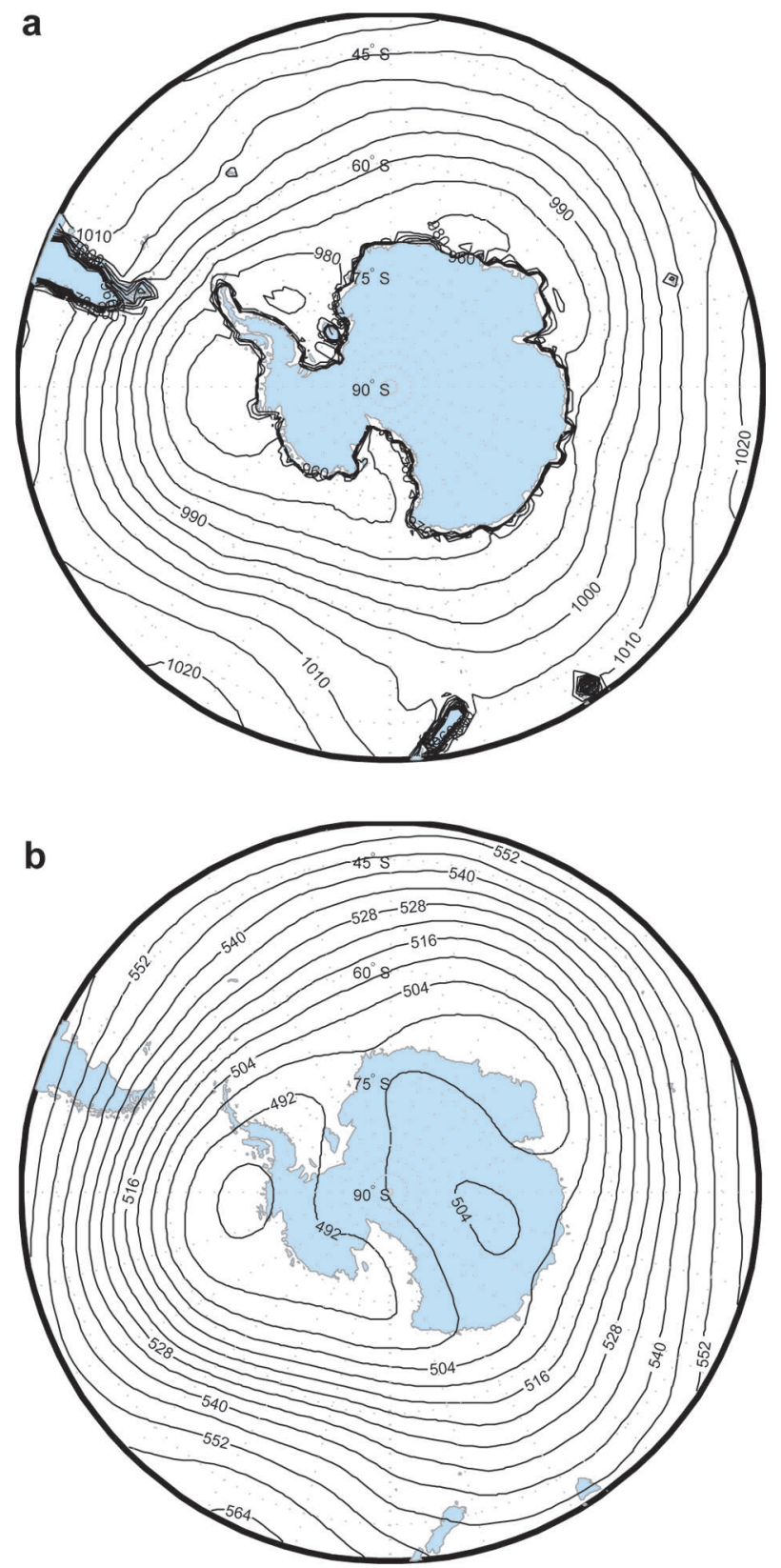

Fig. 2. (a) Mean monthly surface pressure for December 2001. (b) $500 \mathrm{hPa}$ geopotential height for December 2001. (Data from ERA-Interim.)

Antarctic Peninsula connected to an upper-level low leads to a predominantly northerly surface wind above the western Weddell Sea (clockwise circulation around the cyclone on the Southern Hemisphere). Taking into account the surface part of Ekman flow, this causes a movement of the sea ice to the southeast, leading to the observed anomalies in sea-ice concentration and extent. The ice is being pushed towards the DML coast, whereas in the northwestern part of the Weddell Sea negative concentration anomalies of up to $50 \%$ are observed. The commonly observed coastal polynyas of Coats Land are closed. The northerly flow component was dominant above most parts of the Weddell Sea for nineteen days in December 2001; five days of the month showed a mainly southerly flow, which was weak; and on seven days the flow was partly northerly, partly southerly over the Weddell Sea. Since the monthly means show a fairly smoothed picture, in Figure 3 we show an example for the 

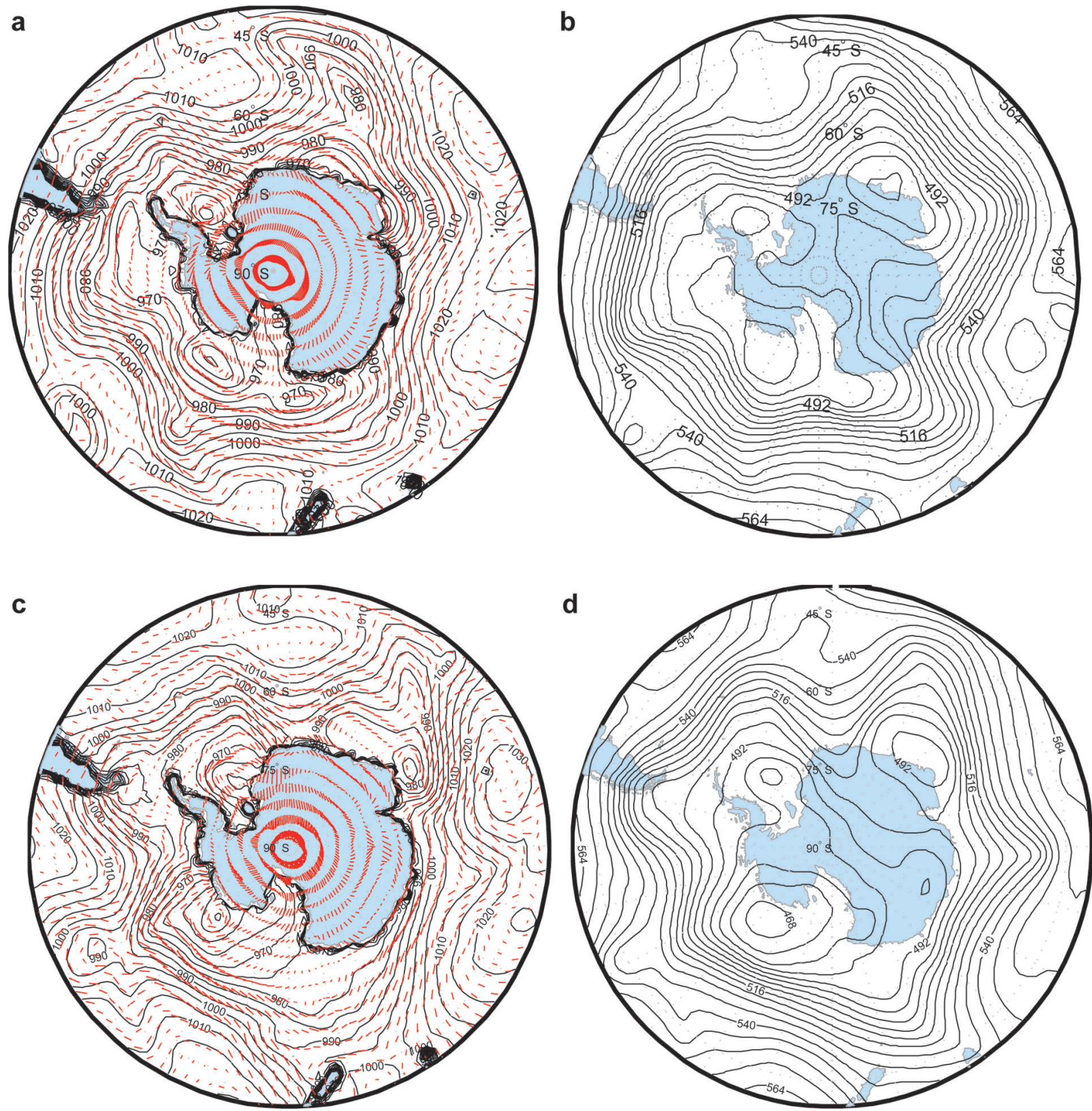

Fig. 3. (a) Surface wind and surface pressure at 1200 UTC on 5 December 2001. (b) $500 \mathrm{hPa}$ geopotential height at 1200 UTC on 5 December 2001. (c) Surface wind and surface pressure at 1200 UTC on 6 December 2001. (d) $500 \mathrm{hPa}$ geopotential height at 1200 UTC on 6 December 2001. (Data from ERA-Interim.)

typical flow in December 2001: surface wind and surface pressure (Fig. 3a and c) and $500 \mathrm{hPa}$ geopotential height (Fig. 3 b and d) for 1200 UTC on 5 and 6 December 2001, respectively (from ERA-Interim). On 5 December, a lowpressure system centered in the western Weddell Sea and the corresponding upper-level low led to a strong northwesterly flow above the eastern Weddell Sea and the adjacent ocean to the north (Fig. 3a and b). On the following day, the centre of the low had moved eastward and the trough above the Weddell Sea had deepened, intensifying the northwesterly flow towards DML (Fig. 3c). This northwesterly flow advected relatively warm, moist air and led to a high-precipitation event in DML (see below). On the western side of the lowpressure system, winds are predominantly southerly, which, taking into account Ekman surface flow, drives the sea ice towards the Antarctic Peninsula.

Figure 4 shows the sea-ice concentration anomalies for March-December 2002. The clearly negative anomalies in the northwestern Weddell Sea can still be seen in May, and then the influence of the atmospheric conditions of the summer slowly disappears, until in December 2002 a strong positive anomaly in sea-ice concentration is observed.

\section{Extremely positive anomaly in sea-ice extent (December 2002)}

As also shown in Figure 4, a strong positive anomaly in seaice concentration is found in the Weddell Sea in December 2002. In the northern and northwestern parts, the anomalies reach values larger than $50 \%$. Almost no negative anomalies are found, except for some areas off the Princess Martha Coast. In Figure 5, the mean monthly surface pressure (Fig. 5a) and the $500 \mathrm{hPa}$ geopotential height (Fig. 5b) from ERA-Interim are again shown. In this case, a weak highpressure ridge is situated above the Weddell Sea, with the ridge axis just slightly east of the Antarctic Peninsula, corresponding to a predominantly southerly flow at its 
March 2002

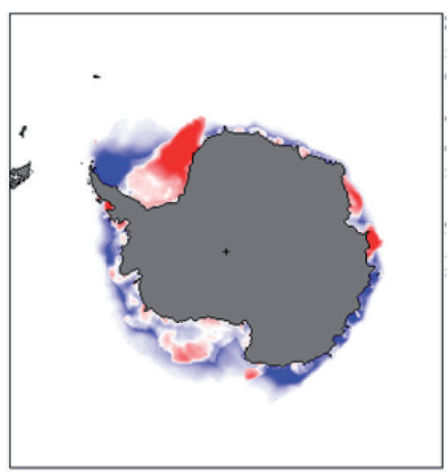

May 2002

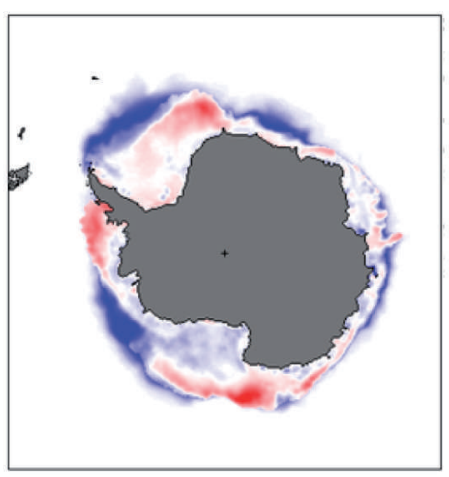

July 2002

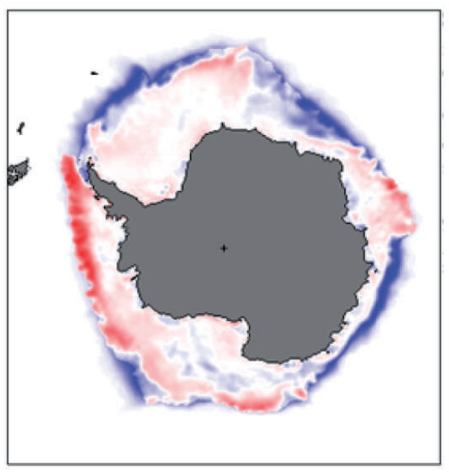

October 2002

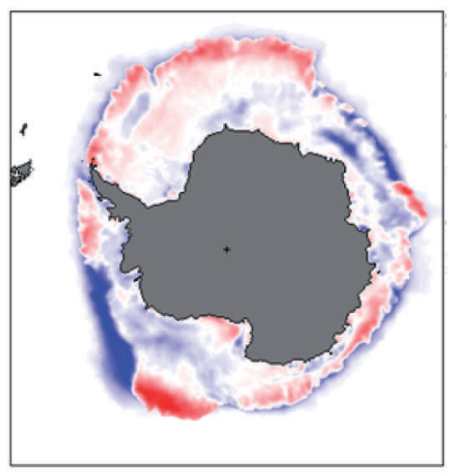

April 2002

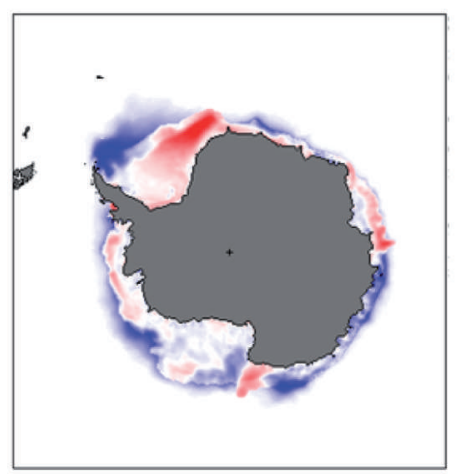

June 2002

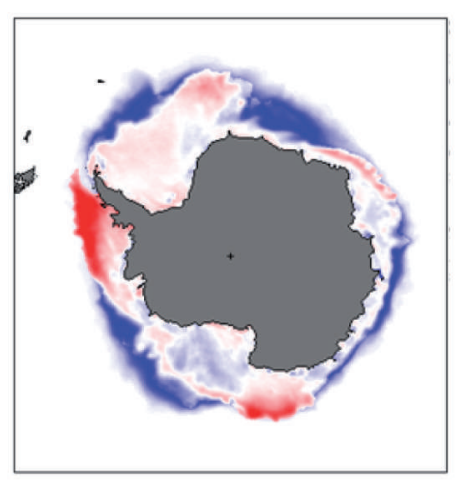

August 2002

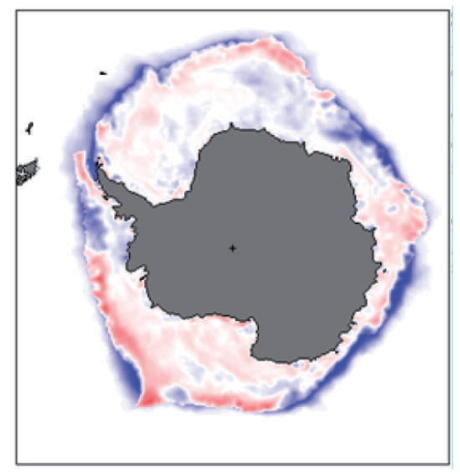

November 2002

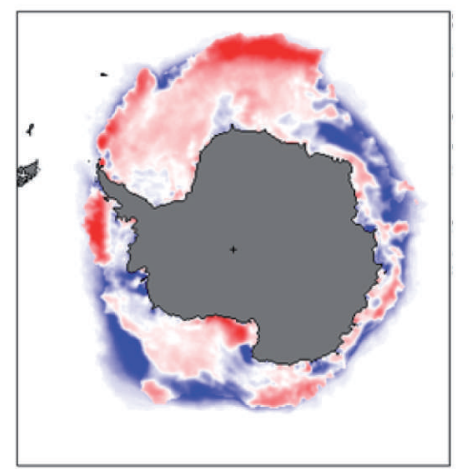

$>50$

45

40

35

30

25

20

15

10

5

0

5

$-10$

$-15$

$-20$

$-25$

$-30$

$-35$

$-40$

$-45$

$<-50$

$\%$

September 2002

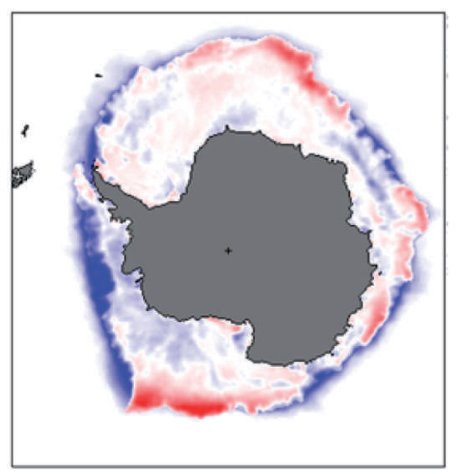

December 2002

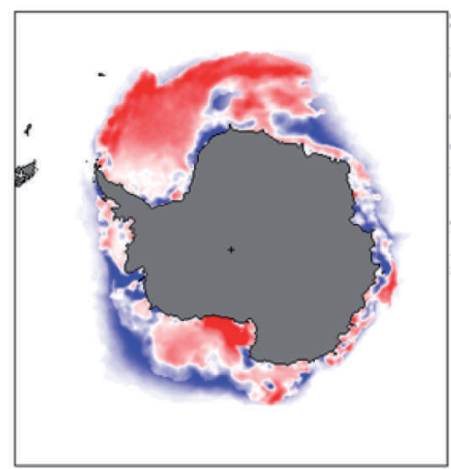

Fig. 4. Anomalies of monthly mean sea-ice concentrations March 2002-December 2002 (data from NSIDC).

eastern edge. This drives the sea ice to the north-northwest, accompanied by new ice formation in the southern Weddell Sea, supported by advection of cold continental air from the south. A predominantly southerly flow was found on fifteen of the December 2002 days; six days showed a relatively weak northerly flow, and on the remaining ten days the flow was partly southerly and partly northerly.

Figure 6 shows an example for this weather situation: the surface pressure map (Fig. 6a) and the corresponding $500 \mathrm{hPa}$ geopotential height (Fig. 6b) at 1200 UTC on 

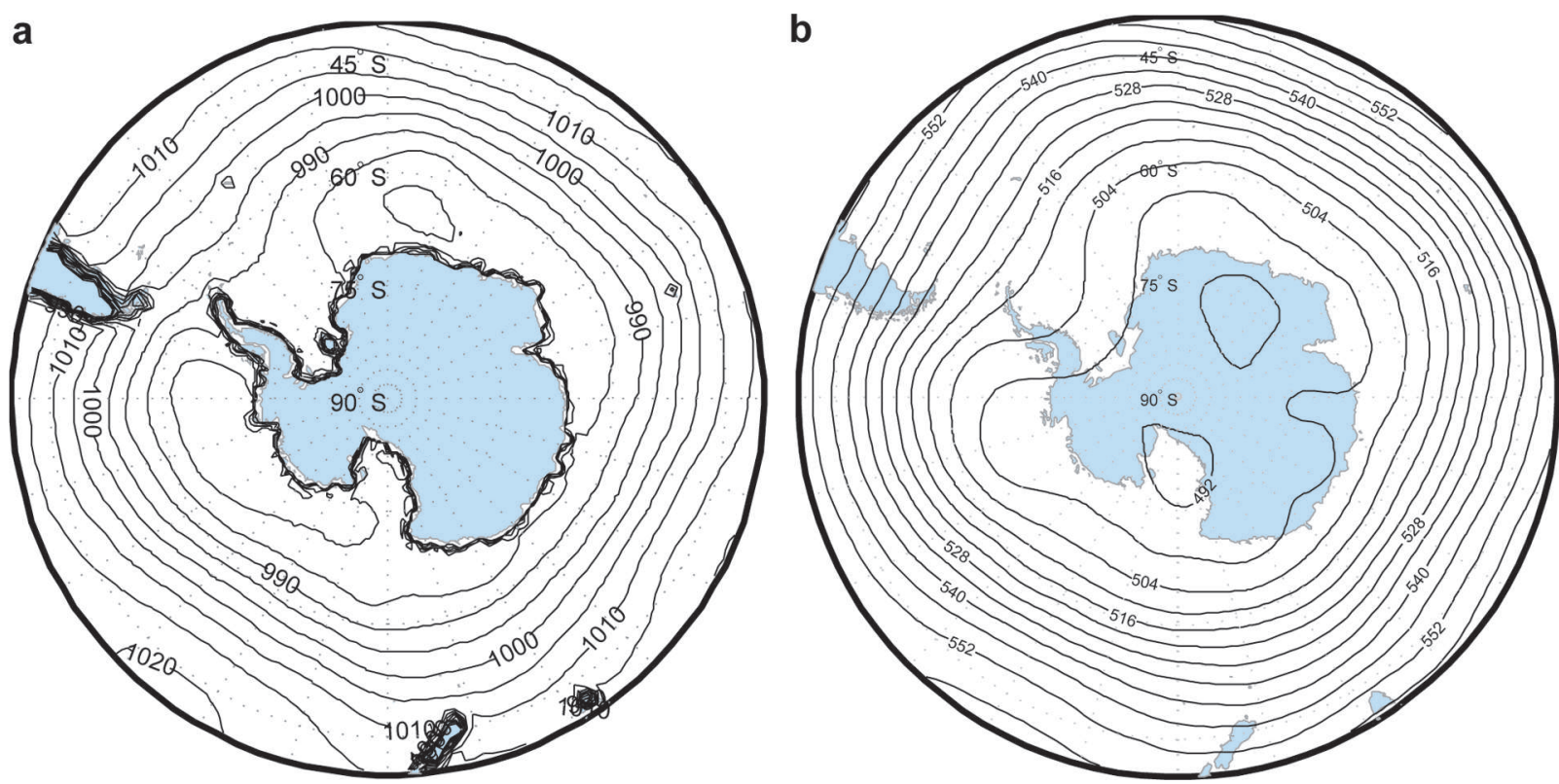

Fig. 5. Mean monthly surface pressure and $500 \mathrm{hPa}$ geopotential height for December 2002 (data from ERA-Interim).

25 December 2002. The predominantly southerly to southwesterly winds over the Weddell Sea drive the sea ice northward. The upper-level flow is less regular, but is mainly southerly as well.

\section{Sea-ice anomalies and stable-isotope ratio in DML}

Figure 7 shows daily precipitation sums derived from AMPS for the EPICA drilling site Kohnen station for 2001 and 2002. The model gives similar results for the whole of west DML. Generally it is found that a few outstanding high-precipitation events per year bring a high percentage of the total annual accumulation. As shown by Schlosser and others (2008, 2010), these events are most often related to amplified Rossby waves connected to a northwesterly flow with advection of relatively warm, moist air. Similar results are found in Wilkes Land, East Antarctica (e.g. Massom and others, 2004). In December 2001 the second week showed extraordinarily high precipitation amounts, with highest values on 5-6 December, whose synoptic situation we discussed above. A further high-precipitation event is seen on 24 December. The synoptic situation (not shown here) was similar to the case of 6 December.

Whereas in December 2001-January 2002 the prevailing northwesterly upper-level flow with advection of relatively warm, moist air caused increased precipitation in DML with several high-precipitation events, in December 2002 the opposite effect is seen. The prevailing south-southeasterly flow advects cold, dry air from the interior of the continent, leading to very low precipitation amounts and no highprecipitation event. For the annual mean $\delta^{18} \mathrm{O}$ measured in the ice core, this clearly means a warm bias in the first period (December 2001-January 2002), since the accumulation
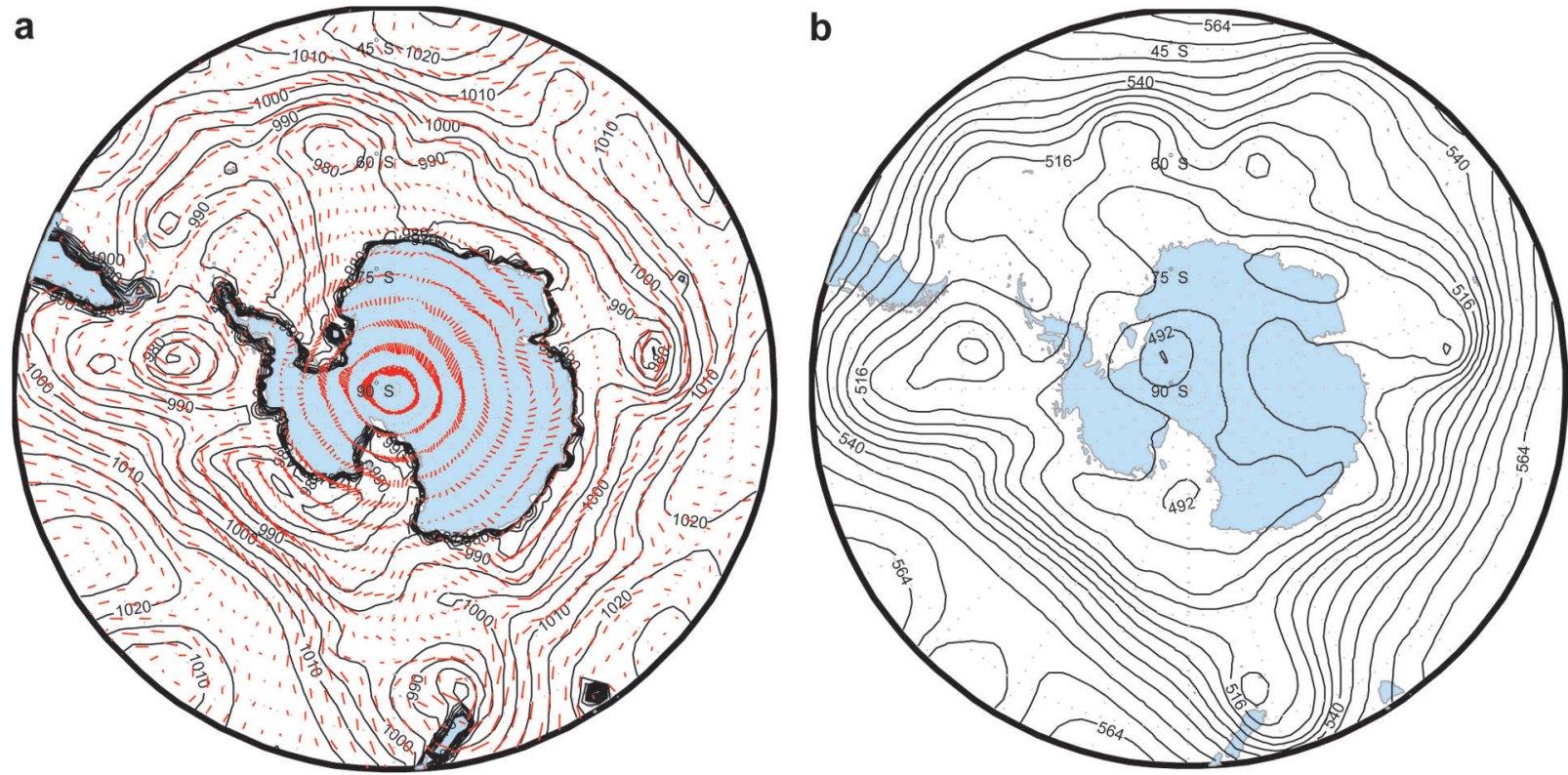

Fig. 6. (a) Surface wind and surface pressure at 1200 UTC on 25 December 2002. (b) 500 hPa geopotential height at 1200 UTC on 25 December 2002. (Data from ERA-Interim.) 
from an extraordinarily warm period (high $\delta^{18} \mathrm{O}$ ) is overrepresented in the annual mean value. The second period (December 2002), however, leads to a warm bias as well, since the extraordinarily cold period is under-represented in the annual mean because the small precipitation amounts with low $\delta^{18} \mathrm{O}$ fall within this cold, dry period.

\section{DISCUSSION}

The examples in this study show that both an extreme positive anomaly and an extreme negative anomaly in seaice concentration can be related to the same feature in the stable water isotope ratio in an interior ice core, namely a warm bias. In the cases presented here, sea-ice concentration was mainly influenced by dynamic rather than thermodynamic processes, even though the advection of warm (cold) air supported the decrease (increase) in sea-ice extent. The dynamics were caused by a relatively stable synoptic situation with amplified Rossby waves, leading to enhanced meridional atmospheric flow. This corresponds to the negative phase of the SAM (Marshall, 2003), which is often used to describe climate variability in the Southern Ocean. The SAM uses the pressure difference between $40^{\circ} \mathrm{S}$ and $65^{\circ} \mathrm{S}$ to describe the strength of the circumpolar vortex. A high-pressure gradient leads to a strong, mainly zonal band of westerlies over the polar ocean, corresponding to little meridional heat exchange and thus a general cooling in most parts of Antarctica. A low-pressure gradient means weak westerlies, corresponding to a more meridional flow and thus heat exchange between lower and high latitudes and consequently generally higher air temperatures in Antarctica. Hall and Visbeck (2002) investigated the influence of the SAM on ocean circulation and sea-ice variations using a coupled ocean-atmosphere model. In the ocean, the stronger westerlies over the circumpolar ocean (around $60^{\circ} \mathrm{S}$ ) also induce a stronger eastward current that leads to a northward Ekman transport south of $45^{\circ} \mathrm{S}$. North of $45^{\circ} \mathrm{S}$ the pattern is reversed due to weaker westerlies. Thus, in their model, sea ice is driven northward when the SAM index is positive, yielding a decrease in ice thickness close to the continent, an increase further north, and generally a larger sea-ice extent than with a negative SAM index. However, this is not confirmed by satellite observations, which show that the positive phase of the SAM is related to non-annular features, namely an increase in seaice extent in the Ross Sea/Pacific sector and a decrease in the Amundsen-Bellingshausen and Weddell Seas (e.g. Lefebvre and others, 2004). Lefebvre and others (2004), in another model study, concluded that the response of the Southern Ocean to the SAM consists of an annular and a non-annular component. For sea ice, the non-annular component seems to be dominant, whereas the annular component mainly influences vertical circulations in the ocean.

According to Noone and Simmonds (2002a), the positive phase of the SAM also leads to a more local origin of Antarctic precipitation, which also influences the stableisotope ratio in ice cores.

However, the SAM index does not give any longitudinal information. The cases investigated in the present study show that the negative phase of SAM can be related to both positive and negative anomalies in sea-ice extent in the same region. There is some topographic influence on the position of troughs and ridges, namely by the Antarctic Peninsula, and also by the three continents reaching into the

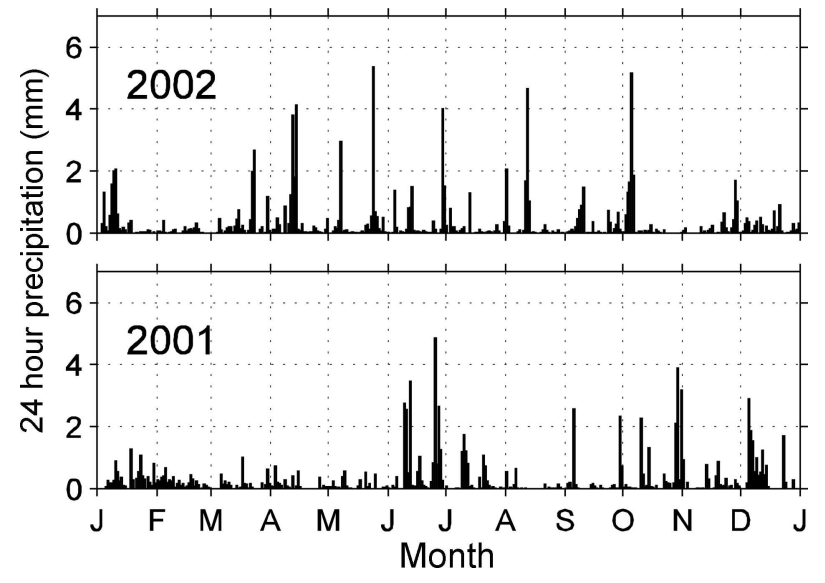

Fig. 7. Daily precipitation sums at Kohnen station in 2001 and 2002, derived from AMPS.

Southern Ocean, leading to a preference of the number 3 wave pattern. This influence might have changed during a glacial climate period with a much more northerly sea-ice edge, though. If, in a colder climate, there had been a preference of certain longitudes for the position of troughs and ridges in an amplified wavenumber 3 pattern, it would have strongly influenced the spatial precipitation distribution and thus the climate information in ice cores. Raphael (2007) showed that the amplitude of the zonal number 3 wave in the Southern Hemisphere decreased when Antarctic sea-ice concentration was reduced. With the present data, it cannot be determined whether a larger seaice extent in a glacial period would have increased the amplitude of the Rossby waves or whether they were possibly shifted northwards. Raphael (2003) also studied the influence of sea-ice concentration on the Southern Hemisphere extratropical atmospheric circulation in summer using a fully coupled climate model. He investigated sea-ice extremes and found that the mid-latitude surface westerlies are weaker in the maximum scenario, while the polar easterlies expand further north. The SAM tends towards positive polarity in the minimum sea-ice scenario.

The findings of Simmonds and Wu (1993) and Pezza and others (2008), namely a southward shift of cyclone activity for a reduced sea-ice extent, would support our hypothesis of a change in spatial/temporal precipitation distribution between glacial and interglacial periods, which must be considered for ice interpretation.

\section{CONCLUSION}

Total Antarctic sea-ice extent shows only small interannual variability, and only a very weak long-term trend is found. On a regional/monthly scale, however, large differences are observed, depending on the prevailing synoptic situation. A stable synoptic situation with amplified Rossby waves can lead to regional extrema in sea-ice concentration and extent. The sign of the anomaly depends on the position of the considered area relative to the axes of the ridge/trough of the amplified wave. A case study of two opposite extrema in the broader area of the Weddell Sea in December 2001 and December 2002, respectively, showed that the sea-ice anomalies can be related directly to the synoptic situation if the SAM is in its negative phase, meaning a weak meridional pressure gradient and thus weak westerlies. 
Considering the effects of these extreme situations on precipitation conditions in the bordering continental areas of DML and the water stable-isotope ratios in ice cores drilled there, it was shown that both positive and negative anomalies in sea-ice extent can be related to a warm bias in the ice core. However, no simple general relationship between sea-ice extent and the stable-isotope ratios in Antarctic ice can be deduced at this time.

\section{ACKNOWLEDGEMENTS}

This study was financed by the Austrian Science Fund (FWF) under grant V31-N10. AMPS is supported by the US National Science Foundation, Office of Polar Programs and the University Corporation for Atmospheric Research (UCAR) and Lower Atmosphere Facilities Oversight Section. Sea-ice data were kindly provided by NSIDC. ERA-Interim data used in this study were obtained from the ECMWF data server. We thank F. Pellet of the University of Innsbruck for support with graphics software. We are grateful to two anonymous reviewers, who contributed constructive comments, as well as to our scientific editor, T. Vihma.

\section{REFERENCES}

Birnbaum, G., R. Brauner and H. Rees. 2006. Synoptic situations causing high precipitation rates on the Antarctic Plateau: observations from Kohnen Station, Dronning Maud Land. Antarct. Sci., 18(2), 279-288.

Bromwich, D.H. 1988. Snowfall in high southern latitudes. Rev. Geophys., 26(1), 149-168.

Enomoto, H. and A. Ohmura. 1990. The influences of atmospheric half-yearly cycle on the sea ice extent in the Antarctic. J. Geophys. Res., 95(C6), 9497-9511.

EPICA Community Members. 2006. One-to-one coupling of glacial climate variability in Greenland and Antarctica. Nature, 444(7116), 195-198.

Gersonde, R., X. Crosta, A. Abelmann and L. Armand. 2005. Seasurface temperature and sea ice distribution of the Southern Ocean at the EPILOG Last Glacial Maximum: a circumAntarctic view based on siliceous microfossil records. Quat. Sci. Rev., 24(7-9), 869-896.

Godfred-Spenning, C.R. and I. Simmonds. 1996. An analysis of Antarctic sea-ice and extratropical cyclone associations. Int. J. Climatol., 16(12), 1315-1332.

Hall, A. and M. Visbeck. 2002. Synchronous variability in the Southern Hemisphere atmosphere, sea ice and ocean resulting from the annular mode. J. Climate, 15(21), 3043-3057.

Heil, P., R.A. Massom, I. Allison, A.P. Worby and V.I. Lytle. 2009. Role of off-shelf to on-shelf transitions for East Antarctic sea ice dynamics during spring 2003. J. Geophys. Res., 114(C9), C09010. (10.1029/2008JC004873.)

Lefebvre, W., H. Goosse, R. Timmermann and T. Fichefet. 2004. Influence of the Southern Annular Mode on the sea ice-ocean system. J. Geophys. Res., 109(C9), C09005. (10.1029/ 2004JC002403.)

Marshall, G.J. 2003. Trends in the southern annular mode from observations and reanalyses. J. Climate, 16(24), 4134-4143.

Massom, R.A. and 6 others. 2004. Precipitation over the Interior East Antarctic Ice Sheet related to midlatitude blocking-high activity. J. Climate, 17(10), 1914-1928.

Noone, D. and I. Simmonds. 1998. Implications for the interpretation of ice-core isotope data from analysis of modelled Antarctic precipitation. Ann. Glaciol., 27, 398-402.

Noone, D. and I. Simmonds. 2002a. Annular variations in moisture transport mechanisms and the abundance of $\delta^{18} \mathrm{O}$ in Antarctic snow. J. Geophys. Res., 107(D24), 4742-4754.
Noone, D. and I. Simmonds. 2002b. Associations between $\delta^{18} \mathrm{O}$ of water and climate parameters in a simulation of atmospheric circulation for 1979-95. J. Climate, 15(22), 3150-3169.

Noone, D., J. Turner and R. Mulvaney. 1999. Atmospheric signals and characteristics of accumulation in Dronning Maud Land, Antarctica. J. Geophys. Res., 104(D16), 19,191-19,211.

Pezza, A.B., T. Durrant, I. Simmonds and I. Smith. 2008. Southern Hemisphere synoptic behavior in extreme phases of SAM, ENSO, sea ice extent, and southern Australia rainfall. J. Climate, 21(21), 5566-5584.

Raphael, M.N. 2003. Impact of observed sea-ice concentration on the Southern Hemisphere extratropical atmospheric circulation in summer. J. Geophys. Res., 108(D22), 4687. (10.1029/ 2002JD003308.)

Raphael, M.N. 2007. The influence of atmospheric zonal wave three on Antarctic sea ice variability. J. Geophys. Res., 112(D12), D12112. (10.1029/2006JD007852.)

Reijmer, C.H. and M.R. van den Broeke. 2003. Temporal and spatial variability of the surface mass balance in Dronning Maud Land, Antarctica, as derived from automatic weather stations. J. Glaciol., 49(167), 512-520.

Röthlisberger, R., X. Crosta, N.J. Abram, L. Armand and E.W. Wolff. 2010. Potential and limitations of marine and ice core sea ice proxies: an example from the Indian Ocean sector. Quat. Sci. Rev., 29(1-2), 296-302.

Schlosser, E. 1999. Effects of seasonal variability of accumulation on yearly mean $\delta^{18} \mathrm{O}$ values in Antarctic snow. J. Glaciol., 45(151), 463-468.

Schlosser, E. and H. Oerter. 2002. Seasonal variations of accumulation and the isotope record in ice cores: a study with surface snow samples and firn cores from Neumayer station, Antarctica. Ann. Glaciol., 35, 97-101.

Schlosser, E., M.G. Duda, J.G. Powers and K.W. Manning. 2008. Precipitation regime of Dronning Maud Land, Antarctica, derived from Antarctic Mesoscale Prediction System (AMPS) archive data. J. Geophys. Res., 113(D24), D24108. (10.1029/ 2008JD009968.)

Schlosser, E., K.W. Manning, J.G. Powers, M.G. Duda, G. Birnbaum and K. Fujita. 2010. Characteristics of high-precipitation events in Dronning Maud Land, Antarctica. J. Geophys. Res., 115(D14), D14107. (10.1029/2009JD013410.)

Schwerdtfeger, W. 1960. The seasonal variation of the strength of the southern circumpolar vortex. Mon. Weather Rev., 88(6), 203-208.

Screen, J.A. and I. Simmonds. 2010. The central role of diminishing sea ice in recent Arctic temperature amplification. Nature, 464(7293), 1334-1337.

Simmonds, I. and D.A. Jones. 1998. The mean structure and temporal variability of the semiannual oscillation in the southern extratropics. Int. J. Climatol., 18(5), 473-504.

Simmonds, I. and X.R. Wu. 1993. Cyclone behaviour response to changes in winter Southern Hemisphere sea-ice concentration. Q. J. R. Meteor. Soc., 119(513), 1121-1148.

Simmonds, I., A. Rafter, T. Cowan, A.B. Watkins and K. Keay. 2005. Large-scale vertical momentum, kinetic energy and moisture fluxes in the Antarctic sea-ice region. Bound.-Layer Meteorol., 117(1), 149-177.

Turner, J., S.A. Harangozo, G.J. Marshall, J.C. King and S.R. Colwell. 2002. Anomalous atmospheric circulation over the Weddell Sea, Antarctica during the Austral summer of 2001/ 02 resulting in extreme sea ice conditions. Geophys. Res. Lett., 29(24), 2160. (10.1029/2002GL015565.)

Van Loon, H. 1967. The half-yearly oscillations in middle and high southern latitudes and the coreless winter. J. Atmos. Sci., 24(5), 472-486.

Wadhams, P. 2000. Ice in the ocean. Amsterdam, etc., Gordon and Breach Science Publishers.

Yuan, X. 2004. ENSO-related impacts on Antarctic sea ice: a synthesis of phenomenon and mechanisms. Antarct. Sci., 16(4), 415-425. 